\title{
Macular pigment in the human retina: histological evaluation of localization and distribution
}

\section{${ }^{1}$ Department of Ophthalmology, St Franziskus Hospital, Münster, Germany}

${ }^{2}$ Institute of Ophthalmology, London, Great Britain

${ }^{3}$ Department of Ophthalmology and Visual Sciences, University of Texas Medical Branch, Galveston, TX, USA

Correspondence: D Pauleikhoff, Department of Ophthalmology, St Franziskus Hospital, Hohenzollernring 74, 48145 Muenster, Germany Tel: 49251 9330831; Fax: 492519330819 E-mail: dapauleikhoff@ muenster.de

Received: 14 November 2006

Accepted in revised form: 13 February 2007

Published online: 30 March 2007

Conflict of interest: These authors state no conflict of interest

\begin{abstract}
Purpose Clinical investigations have demonstrated variation in both the peak optical density and the spatial distribution of macular pigment. To confirm these impressions histologically, the present study examined the distribution of macular pigment in the human retina.

Materials and Methods The macular retina of 11 donor eyes of different ages (28-91years) were examined histologically on $100 \mu \mathrm{m}$ vibratome sections directly, without further staining. Measurements were made in two dimensions: (1) adding the number of macular sections with visible macular pigment, and (2) direct measurement of the extension of macular pigment in the foveolar section, which visibly contained the most macular pigment.

Results The measurements with two methods demonstrated good correlation. The macula demonstrated a variation in the spatial extension of the visible macular pigment between 200 and $900 \mu \mathrm{m}$ diameter around the centre of the fovea, which was also found when direct measurements were taken. There was no correlation with the donor age. The main location of macular pigment was in the layer of the fibres of Henle in the fovea and in the inner nuclear layer at the parafoveal site. Conclusions Histologically, a wide variation of the spatial distribution of macular pigment was found that confirms clinical observations. The primary localization of human macular pigment is in the inner retinal layers. Eye (2008) 22, 132-137; doi:10.1038/sj.eye.6702780; published online 30 March 2007
\end{abstract}

Keywords: macular pigment; oxidative damage; age-related macular degeneration; lutein; zeaxanthin
M Trieschmann', FJGM van Kuijk²,3, R Alexander ${ }^{2}$, P Hermans ${ }^{1}$, P Luthert ${ }^{2}, A C$ Bird $^{2}$ and D Pauleikhoff', ${ }^{1,2}$

\section{Introduction}

Oxidative damage of the central retina caused by retinal irradiation especially by blue light is thought to be an important factor in the development of age-related macular degeneration (AMD). ${ }^{1-3}$ To reduce these damaging processes several antioxidative and protective mechanisms exist in different layers of the central retina. ${ }^{4,5}$ Besides antioxidative vitamins like vitamins $\mathrm{A}, \mathrm{C}$, and $\mathrm{E},{ }^{3,6-13}$ carotenoids such as lutein and zeaxanthin exist in the macula and are visible macroscopically as macular pigment. ${ }^{14-19}$ These substances have two different antioxidative functions in the macula. First they absorb blue light in the inner retina and second they act as free radical scavengers in the photoreceptors. ${ }^{20,21}$

In clinical psychophysical studies a relatively homogeneous spatial distribution of macular pigment has been proposed..$^{22-25}$ This observation was supported in a histological evaluation of the macular pigment in monkeys concluding a uniform distribution of macular pigment in the inner retina without variation between animals. ${ }^{21,26,27}$ However, in recent studies in humans using motion photometry and autofluorescence imaging methods a wide variation was observed in both the foveal peak concentration of macular pigment and in its spatial distribution. ${ }^{28-30}$ The aim of the present histological study was to investigate the localization and spatial distribution of macular pigment in the central human retina and to analyze any interindividual variation.

\section{Materials and methods}

To investigate the localization and distribution of macular pigment in the central human macula, the retinas of 11 human donor eyes of 
different age were examined. The eyes with no evident ophthalmic disorder were obtained from the Eye Bank at the Institute of Ophthalmology, London, Great Britain. The corneas had been removed for transplantation within $48 \mathrm{~h}$ of death. The donors ranged in age from 28 to 91 years. No other information about the donors was available for example concerning their refractive state or race. Our research adhered to the tenets of the Declaration of Helsinki. The globes were immersed in $4 \%$ paraformaldehyde for approximately 4 days and hemidisected. A $7 \times 7 \mathrm{~mm}$ macula specimen was taken with a razorblade and the central retina was separated from the RPE-choroid-sclera complex and the optic disc. In accordance with the method described by Snodderly, ${ }^{26}$ the retinas were embedded in gelatine $25 \%(\mathrm{w} / \mathrm{v})$ gels and sectioned with a vibratome. Consecutive sections of $100 \mu \mathrm{m}$ (5\% variation) thickness were collected.

These consecutive sections were examined unstained. The presence of yellow macular pigment and its localization was analysed by light microscopy immediately after the preparation of the sections, because oxidative processes resulted in a rapid fading of the visible macular pigment at room temperature.

Measurements were estimated in two dimensions: The analysis of macular pigment was performed in consecutive sections and the number of sections with visible yellow macular pigment was recorded and used to calculate the extent of pigment in one direction using the knowledge that each section was approximately $100 \mu \mathrm{m}$ thick (Figure 1). The measurement of the size of yellow macular pigment visible in the central foveolar section of each specimen provides a second estimate of the spatial extension of macular pigment perpendicular to the first.

Images were also acquired through narrow band pass filters at 460 and $530 \mathrm{~nm}$, the spectral characteristics of which are shown in Figure 2. Image acquisition was by way of a monochrome CCD camera and Kinetic Imaging (Liverpool UK) software. Subsequent analysis was carried out using Scion Image (Scion Corporation, MD USA). Scion Image was used to subtract those images, and further detailed information was obtained on the localization of macular pigment. The intensity of the background was normalized in both images before subtraction.

\section{Results}

In the 11 macular specimens the extent of the visible macular pigment in both measurements was very similar and comparable. Its distribution varied between 200 and $900 \mu \mathrm{m}$ in the evaluation of consecutive $100 \mu \mathrm{m}$ vibratome sections and between 180 and $700 \mu \mathrm{m}$ in the analysis of visible MP in foveal sections (Table 1). In some retinas macular pigment could only be detected in an area of $180-300 \mu \mathrm{m}$ diameter around the centre of the fovea, whereas in other individuals macula pigment was visible in a diameter between 700 and $900 \mu \mathrm{m}$ around the centre of the fovea (Figure $3 a$ and $b$ ). The results of the foveal section measurements were always slightly smaller than the analysis of the consecutive vibratome sections, which might be the result of the sections sometimes being more than $100 \mu$ m thick. In addition all sections with visible macular pigment were counted independent of the intensity of the MP, therefore sections

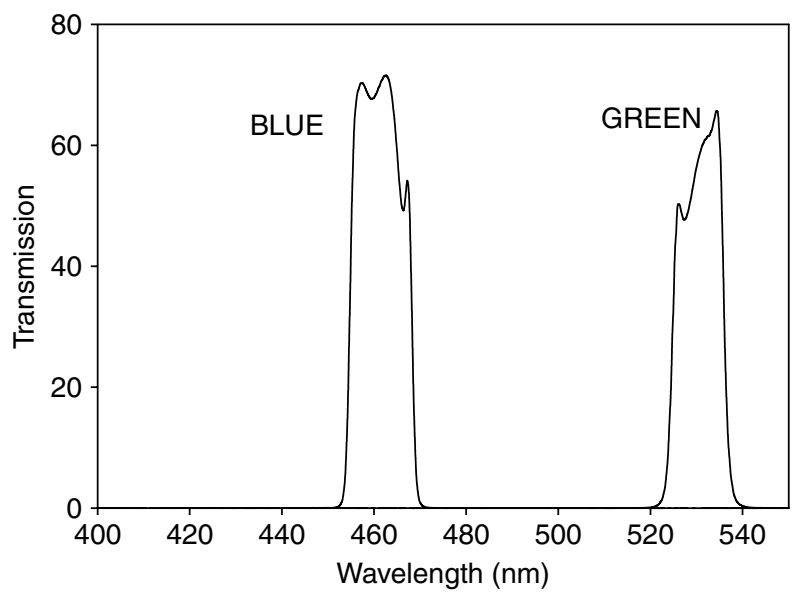

Figure 2 Spectra of narrow band pass filter 460 and $530 \mathrm{~nm}$ used in this study.

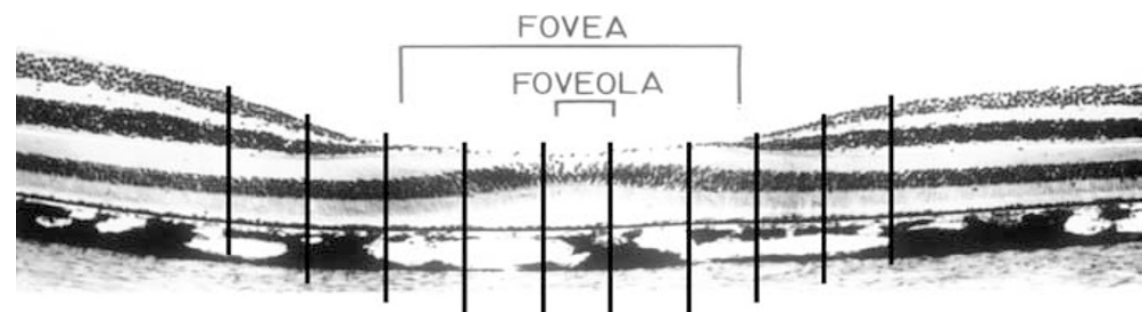

Figure 1 The central human fovea shown as graphics. The vertical lines indicate the localization of consecutive $100 \mu \mathrm{m}$ vibratome sections. 
Table 1 Spatial distribution and extension of visible macular pigment in 11 human retinas of different age

\begin{tabular}{rlccll}
\hline Number & Age (years) & $A(\mu \mathrm{m})$ & $B(\mu \mathrm{m})$ & Central localization & Peripheral localization \\
\hline 1 & 28 & 500 & 480 & LH & INL \\
2 & 45 & 600 & 520 & LH & INL \\
3 & 52 & 600 & 480 & LH & INL \\
4 & 58 & 500 & 440 & LH & INL \\
5 & 61 & 300 & 280 & LH & INL \\
6 & 71 & 200 & 180 & LH & INL \\
7 & 75 & 400 & 320 & LH & INL \\
8 & 76 & 600 & 560 & LH & INL \\
9 & 79 & 900 & 700 & LH & INL \\
10 & 89 & 600 & 625 & LH & INL \\
\hline
\end{tabular}

Abbreviations: LH, layer of Henle; INL, inner nuclear layer A, Size of MP estimated by the number of sections; B, linear extension of macular pigment estimated at central foveal section.

where the MP do not extend completely through $100 \mu \mathrm{m}$ were counted, too.

In this limited group of donors, no relationship between spatial extent of macular pigmentation and age was observed. In particular, there was no consistent decrease in the extent of macular pigment visible with age.

The predominant localization of the macular pigment was in the fibres of Henle and plexiform layers (Figure 3a). Because the fibres have in the outer plexiform layer a horizontal extension into the inner nuclear layer where they synapse onto bipolar cells, in parafoveal sections the macular pigment was also visible in the inner and outer plexiform layers between the cell nuclei of the nuclear layer (Figure $3 b$ ). When the extension of macular pigment was less than $400 \mu \mathrm{m}$, it was not observed in sections more than $200 \mu \mathrm{m}$ from the fovea (Figure $3 \mathrm{c}$ and $\mathrm{d}$ ).

When the sections were photographed with blue light ( $460 \mathrm{~nm}$ filter) the macular pigment appears dark because the light is absorbed (Figure 4a). Subsequently when green light is used (530 $\mathrm{nm}$ filter) the macular pigment is not visualized (Figure $4 \mathrm{~b}$ ). When the image obtained with green light is subtracted from the image obtained with blue light, the localization of the macular pigment is further enhanced as shown in Figure 4c.

\section{Discussion}

To reduce the potentially damaging effects of retinal irradiation, several antioxidative and protective mechanisms exist in different layers of the central retina. ${ }^{4,5}$ Beside proteins like gluthathione these protective mechanisms include vitamins $\mathrm{A}, \mathrm{C}$, and $\mathrm{E}$ and the importance of a reduction in these as potential risk factors for the development of AMD is well supported. ${ }^{3,6-13}$ Carotenoids comprise a large number of different molecules and as a group demonstrate high antioxidative properties. In the retina lutein and zeaxanthin are especially abundant. ${ }^{14-18,27}$ These two compounds have two different antioxidative functions in the macula. First their absorbance spectrum, with specific absorption between 400 and $500 \mathrm{~nm}$, will reduce the amount of incoming blue light and second these molecules have several double bonds and they can act directly as free radical scavengers. ${ }^{20,21,26}$

In the present histological evaluation of macular pigment in the human retina of donors of different ages using a two-dimensional analysis, a variation of the extent of MP between 200 and $900 \mu \mathrm{m}$ was observed. In comparison with studies in monkeys a much wider and larger variation of MP was observed in human macular specimens. $^{21,26}$

The localization of macular pigment within the retina was always consistent with deposition of macular pigment in the fovea in the fibres of Henle, whereas parafoveally the visible macular pigment was located in the inner and outer plexiform layers, where additional axons with macular pigment are located (Figure 4). The results obtained using human retinal sections in this study compare well with those obtained using monkey retinas. $^{21,26}$ The main difference between monkey and human macula is the smaller size of the foveal depression in humans. In most samples we noticed some bending of the retina in the fovea because of the thinner architecture of the retina at that location.

These results support the conclusions drawn form clinical studies that both the distribution and density of macular pigment varies between individuals, and that this does not correlate well with the density at the foveola. ${ }^{28-30}$ This is important in the light of the current interest in the potential role of macular pigment in reducing the risk of visual loss in AMD and the possible manipulation of risk by dietary supplements.

In the assessment of macular pigment both attributes must be taken into account. It is not known if either or 

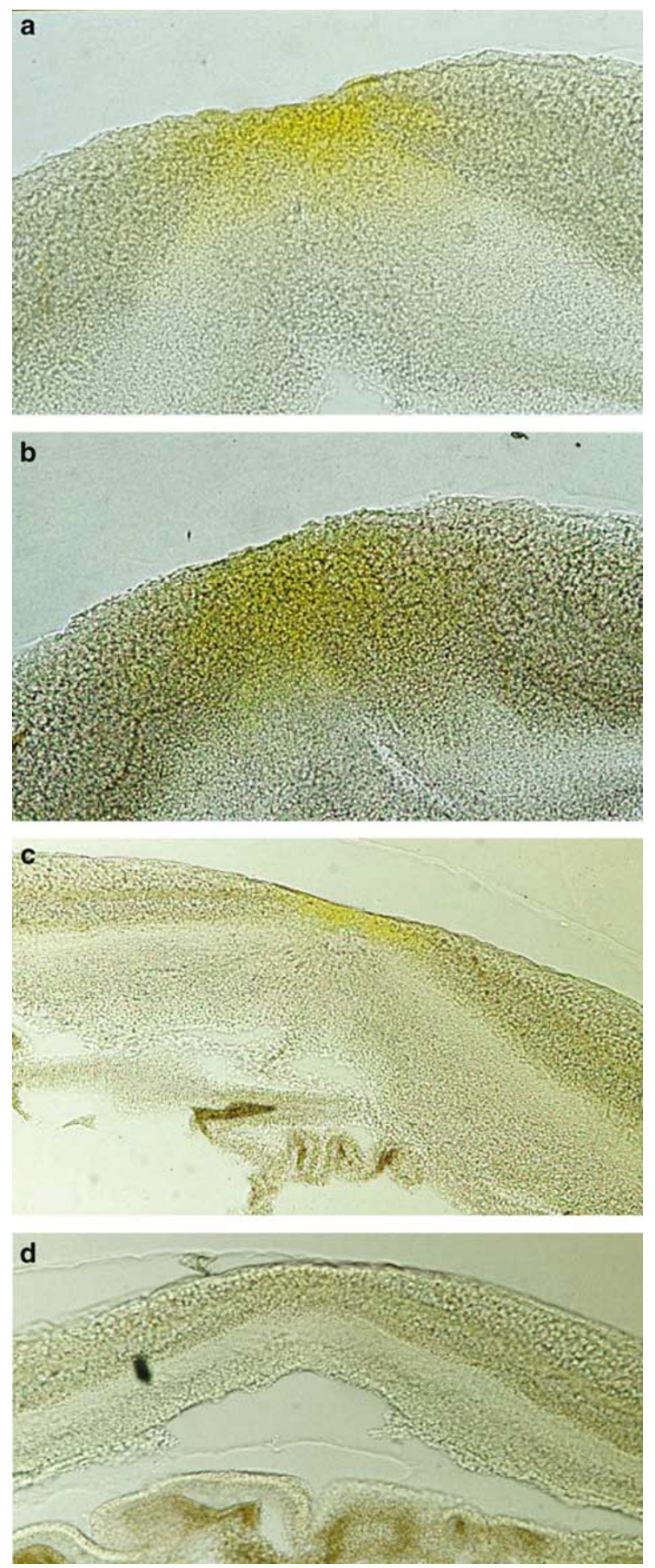

Figure 3 Two examples for the divergent spatial distribution of the macular pigment in the human fovea. The foveal section (a) and parafoveal section with $200 \mu \mathrm{m}$ distance to the centre (b) of specimen 10 Table 1.The MP with an extension about $600 \mu \mathrm{m}$ is well visible in both photographs. In contrast in the case of MP extension of $300 \mu \mathrm{m}$ the MP is visible only in the foveal section (c), but not in the parafoveal section in $200 \mu \mathrm{m}$ distance to the centre (d). (c) and (d) are from specimen no. 5 Table 1. Magnification: $\times 25$.
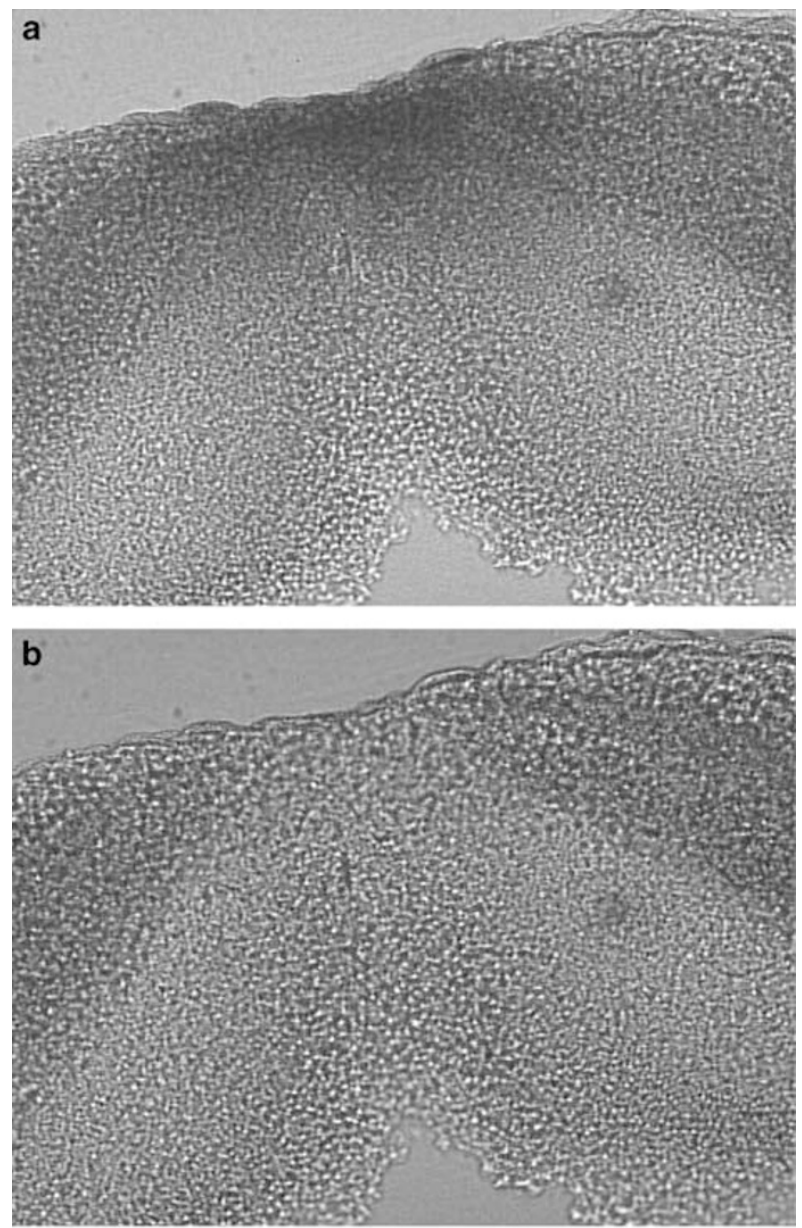

C

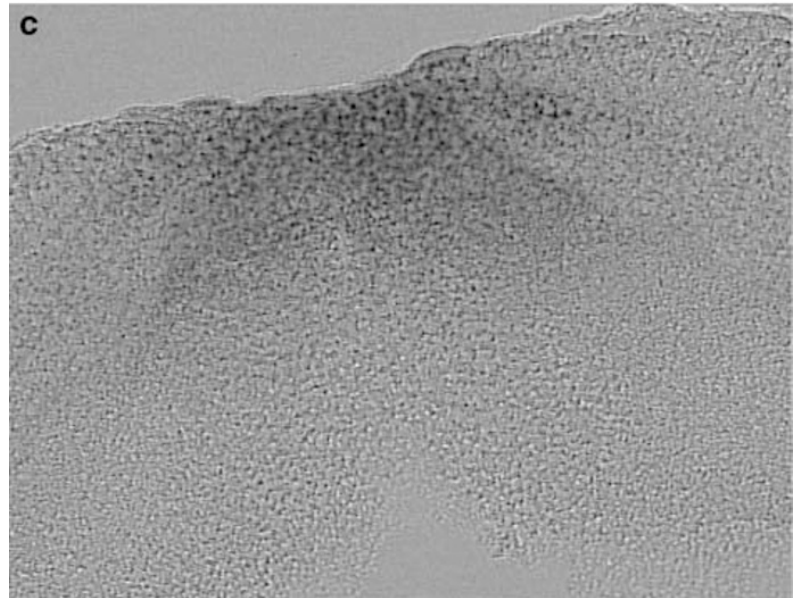

Figure 4 Visualization of the macular pigment in the human fovea by narrow band pass filters. The absorption of blue light by the foveal MP is visible as dark structures using a $460 \mathrm{~nm}$ filter (a). With a filter of $530 \mathrm{~nm}$ the green light is not absorbed by the MP (b). Owing to digitized subtraction of green from blue light photographs only the MP can be demonstrated as dark structures (c). Presence and distribution of MP is shown with more contrast compared to the colour photographs of the same specimen Figure 3a, b. Magnification: $\times 25$. 
both the density and/or distribution is important in protection and can be manipulated by diet. It is also important in certain methods of measuring macular pigment in which the density is assessed by comparing the absorption of light at the fovea and at an eccentric site. If the reference site is not eccentric enough to be outside the region containing macular pigment a false impression may be made. For example, if supplementation causes the density of pigment to rise in the para-foveal region but not at the foveola, measurements may indicate a false impression of loss of macular pigment.

Thus any technique must take into account the density of macular pigment at the fovea and its distribution. In addition this individual specific localization and concentration of macular pigment should be recognized in further studies on the importance of individual variation in the amount of macular pigment as a risk factor for AMD.

\section{Acknowledgements}

D Pauleikhoff and P Hermans are supported by the German Research Foundation (DFG Pa 357/5-2); FJGM van Kuijk is supported by the Foundation Fighting Blindness and by Research to Prevent Blindness; AC Bird is supported by the Foundation Fighting Blindness.

\section{References}

1 Cruickshanks KJ, Klein R, Klein BE. Sunlight and age-related macular degeneration. The Beaver Dam Eye Study. Arch Ophthalmol 1993; 111: 514-518.

2 Cruickshanks KJ, Klein R, Klein BE, Nondahl DM. Sunlight and the 5-year incidence of early age-related maculopathy: The Beaver Dam Eye Study. Arch Ophthalmol 2001; 119: 246-250.

3 Group AREDS. A randomized, placebo-controlled, clinical trial of high-dose supplementation with vitamins $C$ and $E$, beta carotene, and zinc for age-related macular degeneration and vision loss: AREDS report No 8. Arch Ophthalmol 2001; 119: 1417-1436.

4 Beatty S, Boulton M, Henson D, Koh HH, Murray IJ. Macular pigment and age-related macular degeneration. $\mathrm{Br}$ J Ophthalmol 1999; 83: 867-877.

5 Beatty S, Koh H, Phil M, Henson D, Boulton ME. The role of oxidative stress in the pathogenesis of age-related macular degeneration. Surv Ophthalmol 2000; 45: 115-134.

6 Delcourt C, Cristol JP, Leger CL, Descomps B, Papoz L. Associations of antioxidant enzymes with cataract and agerelated macular degeneration. The POLA Study Pathologies Oculaires Liees a 1́Age. Ophthalmology 1999; 106: 215-222.

7 Delcourt C, Cristol JP, Tessier F, Leger CL, Descomps B, Papoz L. Age-related macular degeneration and antioxidant status in the POLA Study. POLA Study Group Pathologies Oculaires Liees a 1́Age. Arch Ophthalmol 1999; 117: 1384-1390.
8 Goldberg J, Flowerdew G, Smith E, Brody JA, Tso MO. Factors associated with age-related macular degeneration. An analysis of data from the first National Health and Nutrition Examination Survey. Am J Epidemiol 1988; 128: 700-710.

9 Seddon JM, Ajani UA, Sperduto RD, Hiller R, Blair N, Burton TC. Dietary carotenoids, vitamins A, C and E and advanced age-related macular degeneration. Eye Disease case-Control Study group. JAMA 1994; 272: 1413-1420.

10 Smith W, Mitchell P, Webb K, Leeder SR. Dietary antioxidants and age-related maculopathy: The Blue Mountains Eye Study. Ophthalmology 1999; 106: 761-767.

11 Smith W, Mitchell P, Rochester C. Serum beta carotene, alpha tocopherol,and age-related maculopathy. The Blue Mountains Eye Study. Am J Ophthalmol 1997; 124: 838-840.

12 Van den Langenberg GM, Mares-Perlman JA, Klein R, Klein $\mathrm{BE}$, Brady WE, Palta M. Associations between antioxidant and zinc intake and the 5-year incidence of early age-related maculopathy inthe Beaver Dam Eye Study. Am J Epidemiol 1998; 148: 204-214.

13 West S, Vitale S, Hallfrisch J, Munoz B, Muller D, Bressler S, Bressler NM. Are antioxidants or supplements protective for age-related macular degeneration? Arch Ophthalmol 1994; 112: 222-227.

14 Bone RA, Landrum JT, Tarsis SL. Preliminary identification of the human macular pigment. Vis Res 1985; 25: 1531-1535.

15 Gerster H. Review: antioxidant protection of the aging macula. Age Ageing 1991; 20(1): 60-69.

16 Handelman GJ, Dratz EA, Reay CC, van Kuijk JG. Carotenoids in the human macula and whole retina. Invest Ophthalmol Vis Sci 1988; 29: 850-855.

17 Nussbaum JJ, Pruett RC, Delori FC. Historic perspectives. Macular yellow pigment. The first 200 years. Retina 1981; 1: 296-310.

18 Schalch W. Carotenoids in the retina. A review of their possible role in preventing or limiting damage caused by light and oxygen. EXS 1992; 62: 280-298.

19 Snodderly DM. Evidence for protection against age-related macular degeneration by carotenoids and antioxidant vitamins. Am J Clin Nutr 1995; 62(Suppl): 1448S-1461S

20 Kachik F, Bernstein PS, Garland DL. Identification of lutein and zeaxanthin oxidation products in human and monkey retinas. Invest Ophthalmol Vis Sci 1997; 38: 1802-1811.

21 Snodderly DM, Auran JD, Delori FC. The macular pigment. II. Spatial distribution in primate retinas. Invest Ophthalmol Vis Sci 1984; 25: 674-685.

22 Beatty S, Murray IJ, Henson DB, Carden D, Koh HH, Boulton ME. Macular pigment and risk for age-related macular degeneration in subjects from a Northern European population. Invest Ophthalmol Vis Sci 2001; 42: 439-446.

23 Hammond Jr BR, Fuld K. Interocular differences in macular pigment density. Invest Ophthalmol Vis Sci 1992; 33: 350-355.

24 Hammond Jr BR, Woten BR, Snodderly DM. Individual variations in the spatial profile of human macular pigment. Opt Soc Am A 1997; 14: 1187-1196.

25 Werner JS, Donnelly SK, Kliegl R. Aging and human macular pigment density. Appended with translations from the work of Max Schultze and Ewald Hering. Vis Res 1987; 27: 257-268.

26 Snodderly DM, Brown PK, Delori FC, Auran JD. The macular pigment. I. Absorbance spectra, localization, and discrimination from other yellow pigments in primate retinas. Invest Ophthalmol Vis Sci 1984; 25: 660-673. 
27 Snodderly DM, Handelman GJ, Adler AJ. Distribution of individual macular pigment carotenoids in central retina of macaque and squirrel monkeys. Invest Ophthalmol Vis Sci 1991; 32: 268-279.

28 Robson AG, Moreland JD, Pauleikhoff D, Morrissey T, Holder GE, Fitzke FW et al. Macular pigment density and distribution: comparison of a minimum motion method with fundus autofluorescence. Vis Res 2003; 43 . 1765-1775.
29 Trieschmann M, Heimes B, Hense HW, Pauleikhoff D. Macular pigment optical density measurement in autofluorescence imaging: comparison of one- and two-wavelength methods. Arch Clin Exp Ophthalmol 2006; 244: 1565-1574.

30 Trieschmann M, Spital G, Lommatzsch A, van Kuijk E, Fitzke F, Bird AC et al. Macular pigment: quantitative analysis on autofluorescence images. Graefes Arch Clin Exp Ophthalmol 2003; 241(12): 1006-1012. 